\title{
Bredekamp, Horst, Kruse, Christiane, Schneider, Pablo, Imagination und Repräsentation. Zwei Bildsphären der Frühen Neuzeit
}

\section{Claire Gantet}

\section{(2) OpenEdition \\ Journals}

Édition électronique

URL : http://journals.openedition.org/ifha/6487

DOI : $10.4000 /$ ifha. 6487

ISSN : 2198-8943

Éditeur

IFRA - Institut franco-allemand (sciences historiques et sociales)

Référence électronique

Claire Gantet, « Bredekamp, Horst, Kruse, Christiane, Schneider, Pablo, Imagination und Repräsentation Zwei Bildsphären der Frühen Neuzeit », Revue de l'IFHA [En ligne], Date de recension, mis en ligne le 01 janvier 2012, consulté le 22 septembre 2020. URL : http://journals.openedition.org/ifha/6487 ; DOI https://doi.org/10.4000/ifha.6487

Ce document a été généré automatiquement le 22 septembre 2020.

(CIFHA 


\title{
Bredekamp, Horst, Kruse, Christiane, Schneider, Pablo, Imagination und Repräsentation. Zwei Bildsphären der Frühen Neuzeit
}

\author{
Claire Gantet
}

1 Le recours croissant des historiens à l'image, non seulement comme illustration, mais aussi et surtout comme support de leur démonstration, est allé de pair, chez les historiens de l'art, avec une réflexivité croissante sur les fonctions et valeurs de l'image. Issu d'un colloque organisé en 2007 à l'université Humboldt à Berlin, le recueil collectif édité par H.B., C.K. et P.S. interroge la dimension épistémique de l'image ou plus précisément, les glissements et passages de l'imagination vers l'image factuelle. Il articule cette problématique en cinq temps, qui font l'objet de cinq parties : 1) la connaissance de soi et du monde, 2) les conceptions et inventions de l'image, 3) l'effet de l'image, 4) images et textes, 5) technique de l'image.

2 La première partie se décline en trois contributions très différentes les unes des autres. T. Leinkauf souligne la complexité de la réflexion sur l'imagination, qu'on ne peut réduire à un dualisme opposant Aristote à Platon, et à son influence chez Giordano Bruno. T. Klemm s'attache au problème, déjà illustré par d'autres études, de l'« argumentation visuelle ", d'après l'exemple de l'image dans la pratique anatomique de Dryander (Johann Eichmann). V. Tkaczyk sonde le complexe des métaphores du vol ou de la mouvance, dérivé d'une perception du monde, au XVIIe siècle, non comme une image, mais comme un théâtre d'images conflictuelles, et le relie aux décryptages afférents de la pensée.

3 La deuxième partie lie le thème des portes et fenêtres ouvertes chez Alberti à la métaphore épicurienne de l'ouverture de nouvelles connaissances et l"attention'. P. Schmidt attire l'attention sur l'incidence de la reproductivité des images, à partir du XVe siècle, sur l'autorité qui leur est accordée. $\mathrm{M}$. A. Bass reprend l'idée de la mouvance des images, cette fois d'après l'exemple des fontaines fantastiques des dessins de Jacopo 
Bellini, qu'elle rapproche des conceptions contemporaines de l'esprit animal dans les fonctions intellectuelles. M. Burioni analyse le dispositif architectural de la Galerie des Offices et son orientation sur des armoiries, " point nul de la représentation ». C. Oberstebrink sonde les fonctions attribuées à l'imagination dans la création artistique, tel qu'il est présenté dans la critique d'art anglaise de la fin du XVIIIe siècle.

4 La troisième partie étudie l'image, le texte ou le théâtre générant des affects. C. Kruse souligne l'importance de la considération de l'image et des interactions avec elle, bref, de l'expérience de l'image. E. Fischer-Lichte souligne de même le rôle constitutif des affects dans les dispositifs théâtraux.

La quatrième partie s'attache aux combinaisons de mots et d'images et à leurs visualisations, ainsi chez Pieter Bruegel (T. Michalsky), Rabelais et Bruegel (S. Laube), et pour les horloges magnétiques (interprétées comme autant de textes par A. MayerDeutsch).

6 La dernière partie décrit divers exemples de techniques de l'image : la représentation de la proportion dans les théories de l'harmonie et de l'art du XVIe siècle (P. Sanvito), le frontispice d'un traité de Christoph Scheiner daté de 1631 (M. Pratschke), enfin l'œuvre d'Athanasius Kircher, illustrant la mouvance des images et la recherche des affects propres à l'image (L. Burkart).

7 Tout recueil d'actes brasse une matière plus ou moins hétéroclite. Celui-ci ne fait pas exception, et les exemples souvent très finement analysés qui y sont traités auraient gagné en intérêt et en force persuasive s'ils avaient été étayés par une réflexion plus riche et plus précise sur les concepts maniés. L'introduction de cinq pages et demi, par H. Bredekamp, C. Kruse et P. Schneider, ne fait qu'annoncer et résumer les contributions. Certaines contributions perdent même de vue la thématique de l'imagination. De façon générale, on regrette que ce volume n'ait pas donné de voix aux historiens ou historiens des sciences, spécialistes des facultés de l'âme à l'époque moderne. Ceci peut inciter les auteurs du volume à poursuivre leur réflexion, en la précisant et en la cadrant sur quelques exemples contextualisés.

8 Claire Gantet (université Paris I, Akademie der Wissenschaften zu Göttingen, Arbeitsstelle in München Ludwig-Maximilians-Universität München) 